\title{
What is my Child Learning at Elementary School? Culturally Contested Issues Between Teachers and Latin American Families
}

Judith K. Bernhard

Ryerson University

Marlinda Freire

University of Toronto

\section{Please Cite:}

Bernhard, J. K., \& Freire, M. (1999). What is my child learning at elementary school? Culturally contested issues between teachers and Latin American families. Canadian Ethnic Studies, 31(3), 72-94.

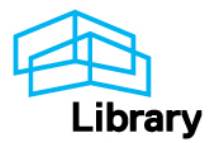




\title{
JUDITH K. BERNHARD AND MARLINDA FREIRE
}

\author{
What is my child learning at elementary school? \\ Culturally contested issues between \\ teachers and Latin American families
}

\section{ABSTRACT/RÉSUMÉ}

This study is part of an extensive research project on children of Latin American immigrants. their teachers and families. Through participant observation in one designated Canadian school, we captured the perspectives of ten students, their parents and teachers. An additional thirty-five families from other elementary schools in Toronto were interviewed to test the trustworthiness of the initial analysis. From the stories of these families and our knowledge of their children's schools, we describe how the parents' practices interact with mainstream practices and how the former are constructed within the present school system. Findings reported include: 1 ) Issues in communication involved teachers' use of educational terms that the parents did not understand. Teachers' positively slanted reports of the children's progress were not understood as indicating the genuine weakness of the child's performance. 2) In most cases, the family's support was not effective in helping children improve their grades at school, and this resulted in family conflicts and parents becoming disengaged from their children's academic tasks. 3) Children and parents expected a more personal approach than the teachers provided. It is concluded that a critical interrogation of the structures of educational delivery is needed as well as attention to the perceptions, beliefs, goals and knowledge of minority parents.

La présente étude fait partie d'un projet de recherche approfondi sur les enfants des immigrants de l'Amérique Latine, leurs enseignants et leurs familles. Grâce à l'observation des participants dans une école canadienne désignée, nous avons capté les points dé vue de dix élèves, de leurs parents et de leurs enseignants. Trente-cinq autres familles dans d'autres écoles élémentaires à Toronto ont passé des entrevues afin de vérifier la vérité de l'analyse initiale. En se basant sur les histoires de ces familles et notre connaissance des écoles de leurs enfants, nous décrivons comment les méthodes des parents interagissent avec les méthodes courantes, et comment celles-ci sont conçues à l'intérieur du système scolaire actuel. Les conclusions rapportées comprennent : 1) Les problèmes de communication concernent l'utilisation par les enseignants de termes pédagogiques que les parents ne comprenaient pas. Les rapports orientés positivement des enseignants sur les progrès des enfants n'étaient pas compris comme indiquant la faiblesse réelle de la performance de l'enfant. 2) Dans la plupart des cas, l'appui de la famille n'était pas efficace pour aider les enfants à améliorer leurs notes à l'école. Cela entraînait des conflits et les parents se retiraient des tâches scolaires de leurs enfants. 3) Les enfants et les parents espéraient une attitude plus personnelle que celle offerte par les enseignants. Il a été conclu qu' un questionnement essentiel des structures de diffusion pédagogique est nécessaire, ainsi qu'une attention aux perceptions, aux croyances, aux buts et aux connaissances des parents minoritaires. 
Mrs. Lorca' (speaking of her Nicaraguan Canadian daughter, eight years of age):

I would like to know what it is that Monica needs? Why in the report cards the teacher says she needs more math, more reading and at home ...? Although we don't speak much English, we are always helping her in everything. She always does her homework and knows everything we ask her, but the report card always arrives as if she is failing.

Mrs. Cordoba (speaking of her Guatemalan Canadian son, thirteen years of age):

It is very worrisome that an intelligent child like Roberto needs Learning Centre year after year and does not progress sufficiently to be at grade level; it has been three years already. I am worried that our children are streamed into these programs and the teachers do not say why the problems occur and do not seem to come up with any solutions. I want to know who the teacher is at Learning Centre, what they teach and what he does in that class.

These two Latin American parents have much in common. Both have elementary school-aged children attending the same public school in the downtown area of a large Canadian city in the province of Ontario. They are both refugees who migrated to Canada from Central America in the 1990s. They spend much of their time in improving their socio-economic position. finding suitable housing and employment, and maintaining ties with relatives living in Canada and their native country. Although in Canada they are of low socio-economic status, they try to ensure a brighter future for their children, the next generation. They believe the high aspirations they have for their children will be met largely through extended schooling. Both wonder why their children are below average in academic performance and what prevents them being academically successful at school.

Despite the high aspirations for their children and the great value these parents attach to education, their teachers do not seem to be aware of their concerns. Further, they are at a loss to explain the reasons for the children's below grade-level performance. Close attention needs to be given to parents like Mrs. Lorca and Mrs. Cordoba for whom education is a very high priority but whose efforts to support their children academically have met with little success. A deeper understanding of their experiences, and those of the many families they seem to represent, can shed light on the effect of cultural and linguistic differences between home and school and their effects on the children's academic performance. We can gain a deeper knowledge of how Latino parents could be sufficiently informed to be effectively involved in educational decision-making processes and be more effective in supporting their children's academic development. We can also learn how teachers can address gaps in communication with these and other groups. Teachers are often trusted and looked up to by Latino families and can be a positive force in facilitating the adaptation process and helping to cushion the resettement period (Bernhard and Freire, 1996).

Latin American migrants represent one of the fastest growing groups in Canada and the United States (Coates, Jarratt, and Mahaffie, 1990), and are among the ethnic groups that are most likely to live in poverty in Canada (Kazemipur and Halli, 1998). What is known about their children's academic achievement is disquieting. A Toronto Board of Education survey (Brown. 1994) showed that Latin American 
children, along with Portuguese, Black and African students, had disproportionately low academic achievement as reflected in their assignment to Basic level programs. Further, a Toronto high-school study (Drever, 1996) reported that Latin American youth become disengaged from school at a rapid pace and join the ranks of students who drop out. If these difficulties are not addressed, problems ensue for the educational system purporting to serve them, and for the children and their families.

Emphasizing the voice and life stories of Latin American families, this article presents our understanding of parents' and teachers' practices in the education of their children. From the stories of these families and our knowledge of their children's schools, we describe how the parents' practices interact with mainstream practices. The former have effects based upon how the educators and teachers construct and interpret them. Although we note parents' education levels in the examples below, we are precluded, on the present data, from being able to assess the relative contribution of their culture versus their level of education. This is not a comparative study but we do not rule out possible similarities with other ethnic groups. We illustrate, from the parents' experiences, the structural constraints they encounter. Where we identify parents' lack of knowledge of the Canadian educational system, we nevertheless assume it is an important responsibility of professionals in the educational setting to clarify that system for newcomer families; both teachers and parents need to find ways of working together as this is an interactive process. Learning about the educational system is one of the many things to be learned in the new country, a process that needs to be facilitated by the educational system.

\section{Theoretical Framework}

In seeking to understand the children and families in our case studies, we consider their systemic disadvantage according to multiple underlying dimensions including those based on class, race, ${ }^{2}$ gender, and ethnicity. We do not consider groups (e.g., Latinas) in terms of essences, but in terms of process and relations routinely enacted and continuously constructed $(\mathrm{Ng}, 1993)$. We situate our investigation in the context of families' and teachers' processes of interaction in a society, and more specifically in an institution where power is diffused in everyday practices and relationships (Apple, 1992; Foucault, 1972; Ng, 1993). Institutional discourses reflecting such relations represent the legitimization of knowledge of the dominant groups and are a foundation for the experiences we call schooling. The dominance of groups, as in Bourdieu's (1986, 1994) theory, is established through the determination of cultural capital based on a set of valorized dispositions and abilities (habitus). The role of such capital in primary schooling is elaborated in Lareau (1989). She suggested that social class differences in family life have a strong effect on children's achievement and aspirations. The children's outcomes are affected by lack of match of cultural capital with the demands of the school. Based on Lareau's analysis, the kind of support teachers expect of parents and children is that of the middle class. Applying the approach more generally, we propose to examine a cultural basis for mismatch of expectations.

There is an extensive literature on the positive impact of parental involvement on children's educational outcomes (Toronto Board of Education, 1991; Ziegler, 1987). 
A number of studies have documented that meaningful teacher-family relations are even more critical when parents and teachers come from different cultural and racial backgrounds because the two stakeholder groups are likely to differ in their approaches to child rearing (Holloway, Fuller, Rambaud, and Eggers-Piérola, 1998; Okagaki and Sternberg, 1993; Sjölund, 1973; West, Hausken, and Collins, 1993). Studies have demonstrated the positive impact of parent involvement on minority children's educational outcomes (e.g., Ada, 1998; Delgado-Gaitan, 1990; Diaz Soto, 1997: Trueba, 1984).

Yet parental involvement is often promoted too glibly. It is not a magic solution to all difficulties, and indeed the concept itself is problematic (K. Dehli, personal communication, August 20, 1998). First, the ways in which parents participate may not be considered by educators to be the proper kind of involvement. Second, immigrant parents in many cases may not know that they can advocate on behalf of their children or that they can influence teachers to customize their children's programs by requesting certain meetings or addressing their concerns in certain ways. A third point regards class bias. As Dorothy Smith (1987) noted, educational efforts to involve parents have often required a particular educational level; lacking that, the parents are found to be unable to give the prescribed forms of assistance in school. It is not surprising then, that there is mounting evidence of particular problems in relations between teachers and diverse parent communities (Bauch, 1992: Bernhard, Lefebvre, Kilbride, Chud, and Lange, 1998).

In the present paper, we address the following research questions:

1. What are problem areas in communication between teachers and families of Latin American children (e.g.. terminology, frequency, type and number of contacts)?

2. What kinds of support do the families provide for their children and how effective are these?

3. What are the expectations of the families and teachers regarding their respective roles?

\section{Methodology}

This study is part of an extensive research project on the children of Latin American immigrants, their teachers and families (Bernhard and Freire, 1996; Bernhard, Freire, Pacini-Ketchabaw, and Villanueva, 1998; Bernhard, Freire, Torres, and Nirdosh, 1998; Bernhard, Lefebvre, Murphy, Kilbride, Chud, and Lange, 1998). The families who are highlighted in this article were part of a two-stage ethnographic study of how forty-five Latin American families support their children's efforts to adapt to the Canadian educational system. The research assistants both emigrated from Latin America after completing high school. Now living in Canada, they are enrolled in doctoral programs in educational theory. The second author completed her medical studies in Chile and moved to Canada where she completed postgraduate training in psychiatry. (She works for a school board as Chief Psychiatrist.) The first author lived in Chile until sixteen years of age and moved to Puerto Rico and then to Canada. Upon receiving her doctorate, she became a professor in the area of education. Because of the authors' familiarity with the language and culture of the 
participants, it was our intention to use what has been called action research (Lather, 1986) and participant observation methods, described as follows. All family interviews were conducted in Spanish.

\section{Stage One: Exploratory Study}

In Stage One we assessed the context of the educational system in one particular elementary school in Toronto and developed an in-depth understanding of all the actors involved (i.e., children, teachers, support staff, principal, vice-principal, families). The school was chosen because of its proximity to the homes of Latin American refugees and the principal's reputation for being responsive to family needs. The first two classrooms were selected in consultation with the school principal. The third classroom was selected as a response to the request of a teacher at the school. During three school terms of five months each, we were immersed as participant observers in three classrooms to study the day-to-day practices of the classroom with a particular focus on the Latin American children. We spent three half-days per week in the school, following the Latin American children through their daily routine in academic and nonacademic activities, to recess, gym, special education classes, and the Heritage Language program (Spanish). We collected field notes and tape-recorded all interviews. We also talked formally and informally with school personnel and the children's families over a period of eighteen months during 1996-1998. Our ethnographic method, based on a naturalistic, cultural contextual paradigm (Cole, 1992; Harkness and Super, 1996; LeVine, et al., 1994), applied to the following three components of our work:

\section{Child Consultation}

We sought voluntary participation of all the Latin American children in three designated classrooms and received signed consent forms for all ten children. A Spanish-speaking researcher recorded observations of the children in their daily classroom activities. We also conducted individual interviews with each of the children in the language of their choice and had access to their official school records. Because of length constraints, these data are not presented here (see Bernhard, Freire, Pacini-Ketchabaw, and Villanueva, 1998: Bernhard, Freire, and Lamphier, 1997; Bernhard, Freire, Torres, and Nirdosh, 1998).

\section{Family Consultation}

We had opportunities to interview all ten of the mothers and most of the fathers in their homes. Each fanily interview lasted from two to three hours; a member of the research team interviewed most families twice, two only once. Interviews were conducted in Spanish by two members of the research team. At the beginning of the interview, we explained that the purpose was to understand the children's situation in the school and to find out how we could provide support. During the interview, we sought to establish a non-authoritarian role by engaging in friendly, non-threatening interactions with the families to gain trust and facilitate communication. We guaranteed anonymity and used a number of open-ended questions (e.g., What have been your experiences with the school this term? How do you see your child's progress at school?). After trust was established and permission granted by the family, the interviews were audio-taped. Parents were asked about issues of communication with teachers and parental support for the families. Field notes and tape transcriptions were thematically analyzed. 


\section{Teacher Consultation}

The objective in this component was to investigate the processes by which teachers adapt their curricula and respond to Latin American students, and to document the kinds of issues teachers experienced in working with the children. We worked with the teachers in the designated classrooms and documented their experiences with the children through field notes, classroom observations, and formal and informal interviews outside of the classroom. Interviews were also conducted with the teachers in the Resource Centre and in programs such as English as a Second Language and Heritage Languages (Spanish).

\section{Data Analysis of Stage One}

Analysis was conducted at various points during the data collection stage. The data analysis proceeded in two ways. First we conducted a child-by-child analysis which included the development of codes and patterns for each child. A cross-child analysis was then carried out, which included the identification of common patterns across all children. Cross-referencing for each child, we inspected parents' and teachers' responses for the recurring and overlapping patterns. A set of common themes was identified, and we were careful, in view of the small sample, not to discard issues that might have been raised by only a single respondent. Several themes emerged that were followed up in later interviews and observations. The transcribed interviews were coded to arrive at a set of preliminary findings that were presented at professional conferences for feedback from professionals with similar research backgrounds. Based on feedback obtained on these presentations, we focused on what emerged as the areas of major concern to this population. Further discussions with several of the families obtained corroborating views on the importance of selected areas.

\section{Stage Two: Confirmatory Study}

In Stage Two we involved an additional thirty-five families in the following manner. We contacted several agencies that offer services to the Latino community in Toronto and asked for names of families with school-age children. We contacted the families and informed them of the purpose of the study. We asked all families whose members had not been seen by mental health professionals and had not formally received services for psychoemotional problems to participate, and none of them declined.

\section{Procedure}

After the initial telephone contact and selection, each family was interviewed on two occasions in Spanish at the family's home (each interview lasted two to three hours). After establishing rapport, background information was sought. Parents were then asked questions that had the same content as that described in stage one of the family consultation. Additionally, parents were asked to show us documentation from the school, including report cards and other correspondence, and to explain their content. Behavioural observations were recorded after the interviews.

The families lived in different parts of the city. The vast majority had immigrated since $1985(\mathrm{~N}=36)$ from Central or South America and had children attending public schools in the Toronto area. Background characteristics of all the families are given in Table 1. 
Table 1

Socio-demographic Characteristics of Sample $(\mathrm{N}=45)$

Mothers' Occupation Number in Country of Origin Number in Canada

Financial Advisor/Accountant
Teacher
Nurse
Secretary
Tailor
Seamstress
Retail Sales
Receptionist
Hairdresser
Babysitter/Cleaning
Factory worker
Home parent
Student

$\begin{array}{lc}4(9 \%) & 0(0 \%) \\ 9(20 \%) & 0(0 \%) \\ 1(2 \%) & 0(0 \%) \\ 9(20 \%) & 0(0 \%) \\ 6(13 \%) & 0(0 \%) \\ 0(0 \%) & 5(11 \%) \\ 6(13 \%) & 0(0 \%) \\ 0(0 \%) & 1(2 \%) \\ 1(2 \%) & 0(0 \%) \\ 0(0 \%) & 14(31 \%) \\ 0(0 \%) & 10(22 \%) \\ 5(11 \%) & 11(24 \%) \\ 4(9 \%) & 4(9 \%)\end{array}$

Fathers' Occupation Number in Country of Origin Number in Canada

\begin{tabular}{|c|c|c|}
\hline Computer Analyst & $2(4 \%)$ & $0 \quad(0 \%)$ \\
\hline Veterinarian & $1(2 \%)$ & $(0 \%)$ \\
\hline Lawyer & $1(2 \%)$ & $(0 \%)$ \\
\hline Engineer & $1(2 \%)$ & $(0 \%)$ \\
\hline Geographer & $1(2 \%)$ & $(0 \%)$ \\
\hline Teacher & $1(2 \%)$ & $(0 \%)$ \\
\hline Electrician & $2(4 \%)$ & $(0 \%)$ \\
\hline Decorator & $1(2 \%)$ & $(0 \%)$ \\
\hline Public Administrator & $6(13 \%)$ & $(0 \%)$ \\
\hline Shoe Maker & $1(1 \%)$ & $(0 \%)$ \\
\hline Retail Sales & $5(11 \%)$ & $(4 \%)$ \\
\hline Agriculture & $2(4 \%)$ & $(0 \%)$ \\
\hline Airplane Technician & $1(2 \%)$ & $(0 \%)$ \\
\hline Welder/Carpenter & $2(4 \%)$ & $1 \quad(2 \%)$ \\
\hline Construction & $0 \quad(0 \%)$ & $5(11 \%)$ \\
\hline Computer Repairs & $0 \quad(0 \%)$ & $7(15 \%)$ \\
\hline Cleaning/service & $0 \quad(0 \%)$ & $7(15 \%)$ \\
\hline Veterinary Assistant & $0 \quad(0 \%)$ & $1 \quad(2 \%)$ \\
\hline Student & $1(2 \%)$ & $2(4 \%)$ \\
\hline Factory Worker & $2(4 \%)$ & $5(11 \%)$ \\
\hline
\end{tabular}




\begin{tabular}{lccr}
\hline \multicolumn{4}{c}{ Table 1 (cont.) } \\
\hline Socio-demographic Characteristics of Sample $(\mathbf{N}=45)$ \\
\hline Year of Arrival & Number & Child Age & Number \\
\hline Prior to 1975 & $2(4 \%)$ & $3-6$ years & $7(15 \%)$ \\
$1976-1986$ & $10(22 \%)$ & $6.1-10$ years & $28(62 \%)$ \\
After 1986 & $33(73 \%)$ & $11-13$ years & $10(22 \%)$ \\
\hline
\end{tabular}

\begin{tabular}{lccc} 
Country of Origin & Number & Country of Origin & Number \\
\hline Salvador & $7(15 \%)$ & Ecuador & $7(15 \%)$ \\
Peru & $6(13 \%)$ & Colombia & $6(13 \%)$ \\
Guatemala & $4(9 \%)$ & Chile & $4(9 \%)$ \\
Venezuela & $3(7 \%)$ & Mexico & $3(7 \%)$ \\
Nicaragua & $2(4 \%)$ & Uruguay & $1(2 \%)$ \\
Cuba & $1(2 \%)$ & Honduras & $1(2 \%)$ \\
\hline
\end{tabular}

\begin{tabular}{lcc} 
Education (Country of Origin) & Number of Mothers & Number of Fathers \\
\hline Post-Secondary & $23(51 \%)$ & $19(42 \%)$ \\
High School & $17(37 \%)$ & $7(15 \%)$ \\
Elementary & $5(11 \%)$ & $4(9 \%)$ \\
Not available (single parent) & $0(0 \%)$ & $15(33 \%)$ \\
\hline
\end{tabular}

Because the selection criteria for the families in the two stages of the study were identical and the exploratory findings were supported by the confirmatory study, all findings are reported together.

\section{Findings}

\section{Theme Area 1: Problems in Communication Regarding Educational Assessment}

Parents and teachers had different perceptions about how the children were doing at school. The parents often did not understand key educational terms or the nature and extent of special educational placements for their children. The teachers framed a child's learning in ways that did not satisfy the parents. The views of the respective parties are now examined.

In most cases the parents did not know the meaning of terminology used by the teachers in describing their children's placement at school. During our home interviews, it became evident that the parents did not have a sound understanding of the meaning of many of the terms used in the Canadian educational system. For example. Mrs. Rivera, a Peruvian high school graduate who was quite fluent in English told us how pleased she was that her child was so bright and doing so well ("es tan vivo"). When we inspected school documentation, however, we found out that the child was placed in special education in a remedial program. During our interviews with the families we were often asked to help understand their children's class placement. Oscar's mother said: 
Once they sent me a note saying Oscar was going to go to a special program. At first I thought that was because he was very good. But now I know that here [in Canada] 'special' means something else. When I went to the interview, I realized there was something wrong. The psychologist, the principal and the teacher were there and said Oscar has problems speaking. I was shocked and scared that my son was stupid. Let me show you the report card and maybe you can explain it to me.

In another case, a school principal related to us her concern that one of the fathers in our study had refused to sign a consent form that would allow his child to work with a special reading tutor which could greatly improve his overall performance. When we spoke to him, we found out that upon reading the form and seeing the term "Reading Clinic," he became upset since his interpretation of a clinic was a place for very sick people, a place where his son did not belong.

Other parents did not understand terms such as "withdrawal," "remedial help," "Learning Centre," "Resource Centre," or "modified day program," but were often too embarrassed to ask. This lack of understanding did not seem to reflect a class issue as the families we interviewed came from all educational levels. There were also many abbreviations used such as IPRC (Identification, Placement and Review Committee) and ESL (English as a Second Language) that the parents did not comprehend. They either used the terms in a different sense than did the school personnel, or simply did not know what they were when we talked about them.

The teachers, for the most part, were convinced that, since the parents had signed the consent forms for the children's participation in the programs and often brought interpreters to meetings, they must know what the programs entailed. On the other hand, the parents reported the interpreters were generally not very helpful as the interpreters themselves did not understand the terminology being used and so could not convey the meaning of the terminology to the parents.

The majority of the parents did not know how to read their children's report cards. The positive wording used by the teachers resulted in additional comprehension difficulties for the parents as many did not know how their children were doing at school. Most parents did keep a file with school correspondence and children's report cards, and they often shared these with us. Our analysis of their explanations of the content of report cards showed that many were confused and completely unaware of the extent of their child's educational achievement deficit. In looking over a report card with Marisela's mother, we saw statements such as "needs to begin doing homework" and "is beginning to listen to her classmates." As personnel involved in Canadian education, we understood these comments within the context of the school board's attempts to encourage teachers to phrase their comments in positive ways to protect children's self esteem. Marisela's mother, however, focused on these comments and on the numbers assigned to the academic areas which ranged from 2 (below satisfactory) to 3 (developing appropriately). After reading the report card, this mother believed things were on the right track. The school records indicate that Marisela has a special educational placement, and the teacher was concerned about her. 
Teacher interviews with parents often evidenced a failure in communication in both directions. Parents described situations in which the teacher began the interview by offering a great deal of information they did not understand, even with the help of a translator. Common phrases used included: "She has special needs," "She is working at her own pace," and "She is more involved in social studies." Then the teacher would pause and wait for the parent to give feedback on what had just been reported. A number of parents did not know what to say and felt embarrassed at their lack of understanding. Some of the parents tried to ask questions; how well were the children doing in reading, writing and mathematics and how their performance related to the grade level expectations. These questions, however, were generally not answered directly in the way the parents hoped for. Rather, the responses were perceived to be abstract and diffuse, and this was reported even when the parents had a good command of English.

In interviews and other meetings, some parents did become aware of the relatively low level of their children's achievement. They expressed great concern. Our field notes, however, record one teacher's reaction to being confronted by a father who was unsure what to make of the report card and was trying to find out more about his daughter's situation.

\begin{abstract}
I had an interview with Antonia's father before Christmas. He came with a relative who translated for us, but it was one of those interviews in which a lot gets said in Spanish and I only get a few words in English. I could feel there was some dissatisfaction. You see Antonia is a very diligent worker, but she still is on the low average. I tried to explain to him that he didn't need worry. Sometimes parents think that their kid is the worst in the class. She is not. Certainly there are other children who are at Antonia's level. She's reading at grade one intermediate level. That's a year behind.
\end{abstract}

This excerpt illustrates that the teacher's focus was on trying to make the parent feel better and more relaxed about the situation and not on identifying a problem or a solution. Although the teacher sensed the parent's discomfort, he did not attempt to explain the reasons behind the difficulties or give specific suggestions of how the child's performance could be improved. Further, it is evident that the teacher and parent had a different set of expectations for the child.

\title{
Theme Area 2: Parents' Support for their Children's Educational Efforts
}

\section{Contacts and Interaction with School Personnel}

Parents' efforts in mobilizing resources for their children, though strong, often did not succeed because of limited direct contact with the teachers; the whole pattern appears to have been affected by the parents' lack of knowledge of how the educational system worked. In accord with their culture, the families valued their children's education. Those parents with high educational levels may have valued it even more. Many of these parents had attended universities in the home countries and Saw education as an extension of their culture and of their own personal experiences. Regarding the completion of children's homework, the parents mentioned a number of patterns of support.

Interactions with school personnel were generally scarce and brief. One standard method of interaction was the ten-minute parent interview. These interviews had 
problems relating to educational terminology and assessment that have already been reviewed under theme area one. However, the interview format unintentionally created a number of problems and did not allow the parents to understand the school's approach nor the teacher to appreciate the parents' approach.

One parental strategy at the interview sessions was to ask about specific areas of weakness. For example, a number of parents were concerned that the children's handwriting was illegible. When they asked teachers why there were no calligraphy lessons, they were told this method had been proven not to work; it was important not to stifle the children's creativity and to allow them to learn at their own pace and natural abilities. Other parents suggested possible strategies such as giving the children homework but were told that until Grade 5, it was not considered necessary as the children learn enough at school. One parent described her situation:

Here [in Canada] they get ten sentences for the week, and if she is smart, she learns it all in two days and has nothing to do for the rest of the week. I asked the teacher to give her more homework and she said the child has to learn slowly, little by little, at her own pace. I agree, but if she is capable, you have to encourage her a little more and not waste time.

The meetings usually ended with smiles and handshakes, but the parents left feeling they did not know the level of progress their children were making and so could not adapt their expectations or be realistic in planning for the child's future.

Although many of the mothers were frequent visitors at the school, they did not often chat with the teachers. Rather, parents expressed the belief that the proper time to talk to the teachers was during the scheduled teacher-parent interviews. Typically, one parent reported: "It is now November and I still have not talked to her teacher but I think the teacher-parent interviews will be announced soon."

Other parents believed that talking to the teacher was taking up the teacher's time unnecessarily so they saved these chats for extremely important events. For example, Liliana's mother said:

I only had contact with her the first day ... when each parent was asking whose child is that and then the new teacher introduced herself to us. Since then I went up to her twice, once to tell her Liliana had to go to the hospital with me and then to tell her Liliana had brought home someone else's book.

Many of the parents were concerned about being respectful to the teachers and tried not to get in their way. We heard of many instances where the parents were not in agreement with the teachers and, in accord with cultural practices, did not speak out as they did not want to be rude.

Other parents were more successful in intervening on behalf of their children. Ricardo's mother, for example, dropped by to chat with the teacher frequently. She said she had been lucky enough to meet a man who told her that, to get anything from the school, they had to see that you were physically present on the school premises and willing to pop your head in the door for an informal chat. In contrast, many parents avoided teachers and all school personnel. 
Whenever I find someone at school who can speak Spanish I ask so I know what is going on. I like to know things. Since I don't understand the teacher much, I keep a distance from her, I try to stay far away from her. There are always words I don't understand. I only speak to one other mother who speaks Spanish.

In keeping her distance, this parent generally avoided contact with the teacher and never visited the classroom. Like others, she was only minimally effective in supporting the children.

\section{Comportment}

All the parents believed an important way to prepare children for school was to make sure they were well behaved and had good manners. Parents saw the development of well-disciplined, well-mannered children as one of their main contributions to their children's educational success. Teaching children to be well-mannered and respectful was seen as providing the basis for being successful academically. When asked what is most important for her in bringing up her daughter, Marisela's mother talked about "que sea una niña que sabe portarse bien," "that she be a child who knows how to conduct herself well." In this family, that means a child who does not talk back to adults, is obedient, quiet, respectful and does not hit other children. Marisela's mother told us that the effects of this training have also carried over to the child's school behaviour.

The kindergarten teacher told me she [Marisela] was polite, well mannered ... no teacher has ever called to tell me she hit, she pushed, she pulled hair. No. They have never told me that, not even in kindergarten.

These findings support those of Gallimore and his colleagues (1996) who studied immigrant Latino families in the U.S. Like Gallimore and Goldenberg, we found that the families had a broader approach to education as indicated by their use of the Spanish term "educación":

Almost without exception we found a strong endorsement of what the families consider traditional Mexican values of educación, that include family solidarity, knowing right from wrong, and obedience, and respect for elders. The parents are strongly identified with their heritage.

(Gallimore and Goldenberg, 1996, p. 18)

The notion of educación is itself undergoing change in terms of adapting to the new society. Nonetheless our findings also indicate that this focus was not generally productive in the context of present North American classrooms that are based on rewarding independent, assertive, academically aggressive and socially outgoing children. We wonder if the focus on "educación y respeto" results in children who fail to assert their own views with enough vigour to thrive in a competitive school environment typical of Canadian urban schools.

\section{Assistance at Home}

Many of the parents took time each day to help the children with schoolwork, and there were a number of patterns to this support. The first pattern was to ensure that the child had the time and materials to do homework and to be available for possible questions. Nonetheless, these parents were not involved in the day-to-day aspects of 
the homework and assumed their children would know what they needed to do to complete their homework."'Every night after dinner we sit down, everyone sits at the table. It is time to do homework. Even if they don't bring homework, we sit and practice from the books I borrow on my own [phonics]."

Although these parents provided the setting for the children to do homework, they limited themselves to responding to children's specific questions; One mother said:

I ask the children, is everything OK? Is there a problem? Do you not understand something? Tell me and I will try to explain it to you. If I don't understand and nobody in the house understands, then I say, ask the teacher or if you want I will send a note with you so the teacher can explain it to you again.

A second common pattern of helping children with their homework is illustrated by Sylvia's mother; she reports how she drills her daughter on basic tasks such as pronunciation:

The teacher tells her to write in her journal, so she brings it home to finish and we make her read what she has written and we correct the words that are not well written, or what is redundant we erase and make her do it again ... .

The parents of Gonzalo and Marisela reported similar drilling practices to help their children with mathematics skills. The parents in their respective countries had learned highly specialized procedures for performing mathematical operationssome were teachers or engineers-but they apparently did not have the conceptual basis for the operations of the "new math." They focused on the mechanics of the operations. The children, carrying out the instructions of the math lessons, did not have such a focus, rather, they were concerned with accuracy. The parents, however, could not explain the concepts and the children could not see the relevance of trying to understand the parents' procedure.

This difference often became a source of conflict between parents and children. The children became angry when the parents tried to help and the parents felt their children were being disrespectful and ungrateful. Roberto's mother told us how she resolved the situation: "This house was becoming a war zone so I decided to take away the tension that was ripping the family apart. Now we leave him to do his homework any way, any time he wants to." With some embarrassment, Roberto's mother told us how she had distanced herself from her son's school-related activities to save family harmony. Many parents like her eventually begin to disengage from supporting the child in completing homework. They are likely to disqualify themselves as possible sources of support for the child's performance.

I [Roberto's mother] feel very frustrated when I have to help with the homework, I don't have the skills or knowledge. For example their math is so different from ours. Sometimes we spend three or four hours trying to solve a problem and at the end we do it wrong. Once he brought a problem where he had to figure out how many fruits each friend had eaten. I told him to interview all his friends and then we found that was wrong, he was supposed to use the values from the book. Then he gets mad when I can't help. 
One can sense the enormous frustration of this parent as she attempts to help with tasks which may require additional explanation for those not in the Canadian AngloFrench mainstream.

\section{Reasons for Parents" "Ineffectiveness"}

A possible explanation for the parents' "ineffective" patterns of support and interaction with teachers lies in the fact that many of the parents did not have a network of other Latin American parents with whom they could discuss children's advancement, the sort of skills that were expected of children, and how parents could request that teachers give them frequent and specific reports on children's progress and needs. Michelle's mother told us there was one other Latino child in the class (actually there were three) but since this other mother always said how well her child was doing, Michelle's mother was embarrassed and never spoke to her. Likewise, Catalina's mother told us her nieces attended a Catholic school rather than the public school her children attended. When we asked her how the nieces liked that school she said they never discussed the children's schooling during social visits.

When we probed further to find out why the parents did not talk to other families about their children's educational experiences we found two reasons. First, the parents had a sense that their children were not doing well at school and did not want them to be judged negatively by others in the community. Second, the conflicts created as a result of the academic difficulties were embarrassing and the family would not want to discuss these with others.

The parents we interviewed did not generally understand the value of play that the teachers discussed as a cornerstone of their programs. Angel's mother said:

I think they should lead them more toward study, not just painting and playing all day. I say to him. 'What did you do in kindergarten today?' 'Play.' He just plays with blocks, with cars, just playing all day long. He never comes with something new, something 1 learned today, or look, now I know this. I think they should start to learn letters. Here at home I am teaching him to memorize them. But I think he should be doing this at school.

The parents did not see the reason for allowing the children to play and participate in creative, apparently nonacademic activities.

In sum, many of the parents' efforts were clearly not effective as the children continued to fall further behind. Regardless of their socioeconomic or educational status, they were not aware of what the teachers would consider an appropriately selfassertive and conceptually interesting response on the part of the child. We emphasize that effectiveness is a function of the interaction of both parents and teachers within the institutional context.

\section{Theme Area 3. The Emotional Atmosphere for Learning}

Angel's mother related the following:

He is sometimes away from school for a week or two because of his asthma. She [the teacher] does not even seem to notice, she just continues her activities, she never says to me what is happening, why is the child away? To me this shows she does not give the child any 
importance for being himself. If they are there, fine, if they are away, fine too; if they learn, fine, if not, that's fine too: she just goes on with her program.

According to this typical interpretation, the teacher is neutral or indifferent.

Many parents believed that teachers should have a caring as well as an educational role. They said teachers need to show they care about the children to be effective. This did not appear to have any simple relationship with class or educational level. Many of the mothers spoke of the importance of affective and emotional nurturing [cariño] in the children's learning and upbringing. Their children's experiences of learning at home occur in this caring context, and the parents expect it at school. It has become a prerequisite or matrix environment for learning. Antonia's mother said:

My daughter liked her teacher. Other years some of her teachers have been cold and rigid. The way the teachers relate to the children is very important since it gives them a sense of trust and if they are treated well, the children do not get frustrated and they will learn.

Our observations of the children in the classroom were consistent with the parents' perceptions although our interpretation may differ. We found the classrooms to be conducted in a businesslike way without any special intimacies or favoritism. The teachers showed moderate warmth in their interactions, smiled frequently, and often praised and encouraged the children. It is important to understand that our perception of this ambience is coloured by our knowledge of what to expect in mainstream Canadian classrooms. We did not observe demonstrative expression of affection or efforts to become very personal with the children.

Let us consider the perceptions of the mother of five-year-old Gonzalo. At home, according to his mother, Gonzalo is a calm child who rarely cries. His mother said that when they are together they talk, he is outgoing and listens. On the other hand, his teacher reports the following behaviour at school. "He does not speak; not in English, not in Spanish. When he started to come he would only cry. For months I had to conduct my class with Gonzalo crying here."

His mother believed Gonzalo cried because he was afraid of the teacher and she described her view of the classroom environment as cold and lacking emotional support:

As soon as I left the classroom, he [Gonzalo] would not do any more work ... nothing. Sometimes I would stay in the back just to watch. One day she [the teacher] scolded him, even in front of me, and she sort of yelled at him. He needs a teacher who is more caring. She tells them to do something and says: do it for me now and that's it. Just at that moment she wants it done and, if he does not do it immediately, she talks to him in an angry tone and he immediately shuts off and does not respond. I think she needs to be more understanding, to have more patience with the children.

In Gonzalo's family, warmth and closeness are the foundation for learning. The issue is not the teacher's intentions; rather we are focusing on the classroom environment as experienced by Gonzalo (according to his mother) as not being emotionally supportive. Our observations of the classroom indicate that it is well 
organized, there is a time for each activity and children alternate between structured and unstructured activities. The mother sees this as a businesslike approach that is not conducive to learning for a child his age.

When we were interviewing Marisol's mother, the younger child called out to her three times. The mother corrected her behaviour saying "I am talking to these señoras now so don't interrupt me, mi amor." Rather than using the language of consequences used by most teachers, this mother disciplines by showing what it means to be kind: by using the term 'señoras,' the mother showed the child that we were worthy of respect. Both the child and the parent were used to and expected this type of warm emotional interaction. Marisol's mother described some teachers who were more effective than others. "Now she likes her teacher better. She is very cariñosa, so she always says nice things to her. My daughter likes that, so now she is doing better at school." Now that there was a teacher that fit with the expected pattern (cariñosa), Marisol was able to benefit from academic instruction.

\section{Summary}

Our findings may be summarized as follows:

\section{Research Question 1}

A main issue in communication involved teachers' use of educational terms that parents did not generally understand. The standard methods of communicating children's progress were not comprehended by the parents. Teachers' positively slanted reports of the children's progress were not understood as indicating genuine weakness of the child's performance. Lastly, the format of teacher-parent conferences blocked parents' efforts.

\section{Research Question 2}

For some families, supporting children included asking them about work, encouraging them and drilling. A minority of the parents were successful in meeting teachers and gaining their support in customizing children's programs. In most cases, the family's support was not particularly effective, and this was especially true where parents avoided contact with teachers and other parents.

\section{Research Question 3}

The teachers expected to run a well-organized classroom without shows of personal favoritism or (to their way of thinking) excessive shows of emotion. The warmth and approval of the teachers was moderated and spread evenly among all students. Children and parents expected a more personal approach than the teachers provided, with greater shows of caring. They wanted the students to be related to in a personal and unique fashion and believed this was a prerequisite for academic learning.

\section{Integrative Discussion}

Our findings have special relevance in light of educational reforms proposed by the government of Ontario. Ontario school systems, like those in a number of other countries, are moving in what is stated to be a direction of increased responsivity to 
communities and increased parental input. Our concern is that these initiatives are undertaken in a manner that seems to presuppose mainstream approaches and legitimates existing modes of discourse. What is needed is attention to the perceptions, beliefs, goals and knowledge of minority parents as well as to their customary ways of interacting with such authorities.

We have looked at some specific areas of difficulties in communication between parents and teachers, and we propose these are not isolated difficulties. We have been describing what we see to be the tip of the iceberg in terms of substantial and enduring difficulties that will continue to affect the interaction between Latin American families and teachers in subsequent years. Indeed, it is plausible to predict that many of these children will not ultimately be counted as successes by either the school system's standards or by the parents (for a review of the institutional barriers to success for a number of diverse groups, see Corson, 1998). We believe we saw the beginnings of what will later be called school disengagement or school dropout. The children's difficulties involve at least the following main points.

The parents believe children gained from teachers who were emotionally responsive. The parents complained that their children would not do well in a cool, businesslike environment. As parents sense that their children are in a cool and unresponsive environment and see their own efforts frustrated, they become disengaged from their children's schooling. Having been told that they do not understand school matters, they try to avoid fights with children about their homework by leaving children to their own devices. The home environment thus becomes as cool to the children as the school environment, and the child's diminishing efforts reflect that situation.

The teachers we met were caring, concerned and kind individuals who expressed their sentiments in accord with the standard teacher practices and the norms of the mainstream culture. Therefore the issue of lack of "cariño" (see also Lewis, 1995) has to be understood as a function of the institutional environment. Vogt, Jordan and Tharp (1996) studied the education of Hawaiian children in the Kamehameha Elementary Education Program (KEEP) and described the limitations of the standard means of verbal positive reinforcement. D'Amato (1986), an anthropologist working with the KEEP project, summarized this as follows:

To gain a place in the peer group, a Hawaiian child must show warmth and also prove toughness. Teachers are evaluated by Hawaiian children in the same framework that the children use with one another. To succeed with the children, teachers must show warmth and toughness. Praise and the smile should be the touchstone of relationships; but the smile should also "show teeth," that is, it should be balanced with firmness. (p. 59)

The parents in our sample would have fully agreed with this approach.

Many Canadian schools operate with a certain degree of impersonality despite ordinary expressions of greeting and praise. The result, according to D. Corson (in press), is that often minority youngsters "begin to feel lost in a school where the dominant variety of the dominant language, and all its institutionalized discourse norms, permeate everything and define everything that matters" (p. 7). 
We wish to stress that in making adaptations for cultural groups, stereotypes and broad generalities are to be avoided. Not all our Latino families wished for one particular type of classroom, and within the families themselves, some had more or less formal ways of instructing the children. Similar cautions have been expressed by Laosa (1981) for Mexican American families.

Parents were particularly appreciative of teachers who were friendly toward them, If the parents did not perceive the teachers to be 'cariñosas, 'they often looked for a caring informant to discuss the child's situation. We often found this person to be the secretary of the school office or the International Languages teacher who taught Spanish. These persons, usually of Latin American background, assumed this role on an unofficial basis and had no training in counseling or familiarity with many educational terms. Nonetheless, they played a critical role in helping parents to tap resources and understand the child's situation.

How do we explain the different expectations of parents and teachers with regard to the emotional atmosphere for learning? Teacher education programs involve separate considerations of socioemotional and cognitive development. Teachers are not generally focused on the emotional prerequisites for learning (Matthews, 1998). As noted by Dahlberg, Moss, and Pence (1999), teachers tend to become impersonal technicians who apply the official guidelines of the school.

First she is a technician, whose task is to ensure the efficient production of the institution's outcomes ... transmitting a predetermined body of knowledge to the child or supporting the child's development to ensure that each milestone is reached at the correct age. (p. 67)

Another factor to consider is the high level of initiative and sophistication necessary for parents to make maximum use of educational resources (Dei. Mazzuca, McIsaac, and Zine, 1997). Lareau (1989) has discussed the difficulties of workingclass families in securing customization of children's educational programs. In present day schools, middle-class parents from the mainstream often call upon experts and skillfully advocate their children's cause to the school. They are even willing to challenge school experts by obtaining independent assessments and ultimately have recourse to legal proceedings. The parents in our sample were unwilling to challenge what they perceive as expert opinion. Institutionalized structures and discourse as noted in $\mathrm{Ng}$ (1993) and Foucault (1972) have often effectively silenced parents.

In this small study it was not possible to address a number of possible confounds. It was assumed that we would not be able to disentangle ethnic and cultural factors from race and class. How would we address the contention that the above findings are most closely related to class and socioeconomic status? While the influence of class is not discounted, it is worth mentioning that over half of the parents in this study would be considered professional or middle class in their country. Also, there were no apparent differences with respect to children's difficulties for the parents who were skilled working class as compared with those who were unskilled working class within their Canadian occupation. We saw no evidence that the class advantage of some parents would count decisively against the difficulties we described. Although the numbers do not allow for generalizations, a number of children from highly professional families were having serious academic difficulties. We presume 
that ethnocultural factors are modulated by other variables. For instance, some of the girls' problems were particularly serious, indicating the presence of gender issues.

Further studies are needed to see how Latin American and other ethnic groups are succeeding in the early years of the educational system. The kind of changes that would help the Latino would likely apply to other groups defined in terms of race, class or ethnicity who over generations have chronic and ongoing problems in profiting from the educational system.

The following are suggested steps toward improving the situation: The professionals have to assume the burden of opening up channels of communication. Teachers need to be more aware of how institutional procedures impact on parents. It is also important to realize that commonplace assessments of parental support can be mistaken or self-fulfilling. Assessments based on prescribed ways of interacting can be incorrect.

When teachers communicate with parents, they should avoid speaking in abstract terms or educational jargon. Parents want guidance about what to ask of their children at home. Teachers must make efforts to meet expectations of parents by telling them how they can help.

It would be desirable for teacher education programs to focus on integrative approaches that clearly link socioemotional and cognitive aspects of child development. As well, these programs should move away from the model of teacher as expert. The child's emotional preparedness to learn cannot be separated from the cognitive variables, and teachers in training would do well to become more aware of this axiom. Teacher educators should draw candidates' attention to the critical role of emotional development and encourage them to reflect on how this climate exists in the perceptions of the children and families. Where teachers and children have established emotional connections, we endorse the practice of having a teacher stay with a cohort of children for two or three years.

Those preparing teachers of young children have, in some programs, had the beneficial experience of being given home-visit assignments; we suggest the expansion of such efforts (see Corson, Bernhard, and Gonzalez-Mena, 1998). Student teachers should be encouraged to see how learning occurs in the home (Moll, Amanti, Neff, and Gonzalez, 1992).

It is unfortunate that parents have to rely on secretaries to find out about the children's programs as they generally have no formal training and are assuming great responsibility in taking on this role. We therefore suggest that in districts where there are Latino children, Spanish-speaking teachers be recruited and hired along with bilingual teachers. A similar emphasis on the importance of hiring black teachers is shown in the recommendations of Dei (1996).

Fundamental school reform, while often talked about, has proven elusive. The institutional system of education tends to perpetuate itself, along with the existing power relations on which it is based. In the process of change, misleading, inadequate or even stereotypical perceptions of the beliefs and attitudes of minority groups remain in place. A critical interrogation of the structures of educational delivery has not occurred. It is imperative for educators to rethink views about the role of parents and families and to consider new ways to involve communities in the educational system. 


\section{ACKNOWLEDGEMENT}

Funding for the project described has been generously provided by the Social Sciences and Humanities Research Council of Canada and by Ryerson Polytechnic University. The authors wish to thank all the families and teachers for their participation in the study. We gratefully acknowledge the support of our research assistants, Fidelia Torres and Veronica Pacini-Ketchabaw. Regarding analysis, we are grateful for the helpful comments of our colleagues George Dei, John Lord, June Pollard, Kenise Murphy-Kilbride, David Corson. Janet GonzalezMena and Harold White. Correspondance regarding this article should be addressed to the first author: Dr. Judith Bernhard, Ryerson Polytechnic University, School of Early Childhood Education. 350 Victoria Street, Toronto, Ontario, Canada M5B $2 \mathrm{~K} 3$.

\section{NOTES}

1. All names are ficticious.

2. We have addressed the issue of racial variables interacting with cultural variables in the Latino population in Bernhard, Freire, Pacini-Ketchabaw, and Villanueva (1998), but the topic is not within the scope of the present paper.

\section{REFERENCES}

Ada. A.F. (1988). The Pajaro Valley Experience: Working with Spanish-speaking parents to develop children's use of reading and writing skills through the use of children's literature. In T. Skutnabb-Kangas and J. Cummins (Eds.), Minority education: From shame to struggle (pp. 223-238). Philadelphia, PA: Multilingual Matters.

Apple, M. (1992). The text and cultural politics. Educational Researcher, 21(7), 4-11.

Bauch, P.A. (1992, April). Toward an ecological perspective on school choice. Paper presented at the annual meeting of the American Educational Research Association, San Francisco, CA. (ERIC Document Reproduction Service No. ED 346595 )

Bernhard. J.K., and Freire. M. (1996). Latino refugee children in childcare: A study of parents and caregivers. Canadian Journal of Research in Early Childhood Education. 5(1), 59-71.

Bernhard, J.K., Freire, M., and Lamphier, M. (June, 1997). Methods of field work with refugee population: The experiences of Latin-American children in the Canadian educational system. International Conference on Multicultural/Minority Groups Jerusalem, Israel.

Bernhard, J.K., Freire, M., Pacini-Ketchabaw, V.. and Villanueva, V. (1998). A Latin American parents' group participates in their children's schooling: Parent involvement reconsidered. Canadian Ethnic Studies/Études ethniques au Canada, 30(3), 77-98.

Bernhard, J.K., Freire, M. Torres, F., and Nirdosh, S. (1998). Latin Americans in a Canadian primary school: Perspectives of parents, teachers, and children on cultural identity and academic achievement. Journal of Regional Studiex, 19(3), 217- 236. 
Bernhard, J.K., Lefebvre, M.L., Kilbride, K.M., Chud, G., and Lange, R. (1998). Troubled relationships in early childhood education: Parent-teacher interactions in ethnoculturally diverse settings. Early Education and Development, 9(1), 5-28.

Bourdieu, P. (1986), The forms of capital. In J.C. Richardson (Ed.), Handbook of theory and research in the sociology of education (pp. 241-257). New York: Greenwood Press.

Bourdieu, P. (1994). Social space and symbolic power. In The polity reader in social theory (pp. 111-120). Cambridge, MA: Polity Press.

Brown, R.S. (1994). A follow-up the Grade 9 cohort of 1987 secondary students survey participants. Toronto, ON: Toronto Board of Education.

Coates, J., Jarratt, J., and Mahaffie, J. (1990). Hispanics are the largest fast-growing minority population in the United States. In Future work (pp. 34-46). San Francisco. CA: Jossey-Bass.

Cole, M. (1992). Context, modularity, and the cultural constitution of development. In L.T. Winegar and J. Valsiner (Eds.). Children's development within social context: Vol. 2. Research and methodology (pp. 5-31). Hillsdale, NJ: Erlbaum.

Corson, D. (in press). Language diversity in education. Mahwah, NJ: Erlbaum.

Corson, D. (1998). Changing education for diversity. Philadelphia, PA: Open University.

Corson, P., Bernhard, J.K., and Gonzalez-Mena, J. (1998). Culturally situated explorations of child development: A home visit project for prospective early childhood teachers. Journal of Early Childhood Teacher Education, 19(3), 245-258.

D'Amato, D. (1986). Resistance and compliance in minority classrooms. In E. Jacob and C. Jordan (Eds.), Minority education: Anthropological perspectives (pp. 181-207). Norwood: NJ: Ablex.

Dahlberg, G., Moss, P., and Pence, A. (1999). Beyond quality in early childhood education and care: Postmodern perspectives on the problem with quality. Basingstoke, UK: Falmer.

Dei, G. (1993). Narrative discourses of Black/African-Canadian parents and the Canadian public school system. Canadian Ethnic Studies/Études ethniques au Canada, 25(3). 45-65.

Dei, G. (1996). The role of Afrocentricity in the inclusive curriculum in Canadian schools. Canadian Journal of Education, 2l(2), 170-186.

Dei. G., Mazzuca, J., McIsaac, E., and Zine, J. (1997). Reconstructing dropout: A critical ethnography of the dynamics of Black students' disengagement from school. Toronto. ON: University of Toronto Press.

Delgado-Gaitan, C. (1990). Literacy for empowerment: The role of parents in children's education. London, UK: Falmer.

Diaz Soto, L. (1997). Language, culture and power: Bilingual families and the struggle for quality education. Albany: State University of New York Press.

Drever, N. (1996). Frustrated learners: An ethnographic study of Spanish-speaking students at an inner-city high school in Toronto. Unpublished master's thesis. University of Toronto, Toronto, ON.

Foucauit, M. (1972). The archeology of knowledge and the discourse on language. New York: Pantheon. 
Gallimore, R., and Goldenberg. C. (1996). Accommodating cultural differences and commonalities in educational practice. Multicultural Education, 4(1), 16-19.

Harkness, S., and Super, C. (1996). Parental cultural belief systems: Their origins, expressions, and consequences. New York: Guilford.

Holloway. S., Fuller, B., Rambaud, M., and Eggers-Piérola, C. (1998). Through my own eyes: Single mothers and the cultures of poverty. Cambridge, MA: Harvard University Press.

Kazemipur, A., and Halli, S.S. (1998). Plight of immigrants: The spatial concentration of poverty in Canada. Canadian Journal of Regional Science, 20(1,2), 11-28.

Laosa, L.M. (1981). Maternal behavior: Sociocultural diversity in modes of family interaction. In R.W. Henderson (Ed.), Parent-child interaction: Theory, research, and prospects (pp. 125-167). New York: Academic.

Lareau, A. (1989). Home advantage: Social class and parental intervention in elementary education. New York: Falmer.

Lather, P. (1986). Research as praxis. Harvard Educational Review. 56(3), 257-277.

LeVine, R., Dixon, S., LeVine, S., Richman, A., Leiderman, P., Keefer, C., and Brazeiton. T. (1994). Child care and culture: Lessons from Africa. Cambridge, MA: Cambridge University Press.

Lewis, C.C. (1995). Educating hearts and minds: Reflections on Japanese presechool and elementary education. New York: Cambridge University Press.

Matthews, D.J. (1998). Enhancing learning outcomes for diversely gifted adolescents: Education in the social/emotional domain. The Journal of Secondary Gifted Education, $10(2), 157-168$.

Moll, L. C.. Amanti, D.. Neff, D.. and Gonzalez, N. (1992). Funds of knowledge for teaching: Using a qualitative approach to connect homes and classrooms. Theory into Practice, $21(2), 132-141$.

Ng. R. (1993). Racism, sexism, and nation building in Canada. In C. McCarthy and W. Crichlow (Eds.), Race, identity and representation in education (pp. 50-59). New York: Routledge.

Okagaki, L., and Sternberg, R.J. (1993). Parental beliefs and children's school performance. Child Development, 64, 36-56.

Sjölund, A. (1973). Day care institutions and children's development. Lexington. MA: Heath.

Smith, D. (1987). Women's work as mothers. In R. Miliband (Ed.), Socialist register (pp. 257-277). London, UK: Lawrence and Weinhart.

Super, C.M., and Harkness, S. (1986). The developmental niche: A conceptualization at the interface of child and culture. International Journal of Behavioral Development, $9_{1}$ 545-569.

Toronto Board of Education. (1991). Final report of the work group on parental involvement. Toronto, ON: Toronto Board of Education.

Trueba, H. (1984). The forms, functions, and values of literacy. Journal of the National Association for Bilingual Education, 9.21-38. 
Vogt, L.A., Jordan, C., and Tharp, R.G. (1996). Explaining school failure, producing school success: Two cases. In E. Jacob and C. Jordan (Eds.), Minority education: Anthropological perspectives (pp. 53-65). Norwood, NJ: Ablex.

West, J., Hausken, E.G., and Collins, M. (1993). Readiness for kindergarten: Parent and teacher beliefs. (National Centre for Education Statistics Report No. 93-257). Washington, DC: U.S. Department of Education, Office of Educational Research and Improvement.

Ziegler, S. (1987). The effects of parent involvement on children's achievement: The significance of home/school links. Toronto, ON: Toronto Board of Education. 


\section{CONTRIBUTORS / COLLABORATEURS}

Judith Bernhard

Monica Boyd

Joe Cherwinski is a professor in child development at Ryerson Polytechnic University and has a particular interest in how children fare in child care and school contexts. She is a native of Chile, a lecturer, author, educator, and parent. Since completing her $\mathrm{Ph} . \mathrm{D}$. from the University of Toronto, she has addressed needs of immigrant and refugee children and families through her work with young children, their families and teachers.

currently is the Mildred and Claude Pepper Distinguished Professor of Sociology, Florida State University and previously was at Carleton University, Ottawa for over twenty years. A demographer and sociologist by training, Dr. Boyd's research interests include ethnicity, international migration and gender inequality. She has served on numerous Canadian governmental advisory committees in the general areas of statistics, population, immigration, inequality and the status of women. Dr. Boyd is a past president of the Canadian Population Society.

has taught a wide variety of Canadian History courses while coordinating the Canadian Studies Major Programme at Memorial University, where he has worked since 1971. In 1997 he was presented with the President's Award for Distinguished Teaching for his efforts. Dr. Cherwinski's initial research interest was Western Canadian labour and the left. This proved a logical step toward his work on agricultural labour which resulted in several published articles. Most recently his work has focussed on the relationship between environment and social change, particularly during the winter of 1906-07. 
Marlinda Freire

Loren Lerner

Edward B. Harvey is a psychiatrist with a background in paediatrics who arrived in Canada in 1974 following the military coup in her native Chile. Her primary areas of expertise are immigrants and refugees, second language acquisition, and effects of poverty on mental health. Dr. Freire is an Assistant Professor in the Faculty of Medicine, Department of Psychiatry, University of Toronto, a staff psychiatrist at the Hospital for Sick Children as well Chief of Psychiatric Services at the Toronto School District Board.

is a professor in the department of Art History at Concordia University. She was editor of Canadian Film and Video: A Bibliography and Guide to the Literature/Film et vidéo canadiens : bibliographie et guide de la documentation (Toronto: University of Toronto Press, 1997) and co-editor of Art and Architecture in Canada: A Bibliography and Guide to the Literature/Art et architecture au Canada : une bibliographie et guide de la documentation (with Mary Williamson, Toronto: University of Toronto Press, 1991). Her interest in Canadian artists of eastern European origin connects with her own personal history, to her Russian father and Austrian grandfather who immigrated to Montreal in the early decades of the twentieth century.

is Professor of Sociology at the University of Toronto. His area of specialization is applied social research and policy studies with a particular emphasis in the fields of education, labour markets and international migration patterns. For the past three years he has been directing a research project for the Joint Centre of Excellence for Research on Immigration and Settlement (CERIS) on the socioeconomic situation of immigrants to Canada. 